\title{
Protease-activated receptor-2 induces expression of vascular endothelial growth factor and cyclooxygenase-2 via the mitogen-activated protein kinase pathway in gastric cancer cells
}

\author{
CHENG ZHANG, GUANG-RONG GAO, CHEN-GUANG LV, \\ BOA-LEI ZHANG, ZHI-LI ZHANG and XUE-FENG ZHANG \\ Department of General Surgery, General Hospital of Shenyang Military \\ Area Command, Shenyang, Liaoning 110840, P.R. China
}

Received June 6, 2012; Accepted July 27, 2012

DOI: $10.3892 /$ or.2012.1998

\begin{abstract}
Protease-activated receptor-2 (PAR-2) has shown strong pro-angiogenesis activity physiologically and pathologically. This study aimed to explore PAR-2 regulation of pro-angiogenesis gene expression and the underlying molecular pathways in gastric cancer cells. MKN28 human gastric cancer cells were treated with trypsin, a PAR-2 activator, and subjected to real-time reverse transcription polymerase chain reaction (qRT-PCR), western blotting and ELISA for gene expression analyses. ERK1/2 phosphorylation and p38 MAP kinase inhibitors (PD98059 and SB203580, respectively) were used to block their gene activities. PAR-2 mRNA and protein were expressed in MKN-28 cells and activated by trypsin treatment. Trypsin-activated PAR-2 protein significantly enhanced expression of vascular endothelial growth factor (VEGF) and cyclooxygenase-2 (COX-2) mRNA and protein in gastric cancer cells in a dose- and time-dependent manner. PAR-2 activation also induced the phosphorylation of ERK1/2 and p38 MAP kinase, but the ERK1/2 and p38 inhibitors blocked the activated PAR-2-induced VEGF and COX-2 expression in gastric cancer cells. PAR-2-induced expression of VEGF and COX-2 mRNA and protein in gastric cancer MKN28 cells was mediated by activation of an ERK1/2- and p38 MAP kinase-dependent pathway. Thus, PAR-2 may serve as a promising target for anti-angiogenesis therapy to treat gastric cancer.
\end{abstract}

Correspondence to: Dr Xue-Feng Zhang, Department of General Surgery, General Hospital of Shenyang Military Area Command, 83 Wenhua Road, Shenhe District, Shenyang, Liaoning 110840, P.R. China

E-mail: cz1791@126.com

Key words: gastric cancer, protease-activated receptor-2, vascular endothelial growth factor, cyclooxygenase-2, mitogen-activated protein kinases

\section{Introduction}

Gastric cancer is the fourth most common cancer and the second leading cause of cancer-related death in the world. In China alone, $\sim 463,000$ new patients will be diagnosed with gastric cancer and 352,000 patients will die annually, accounting for nearly half of the new cases and deaths of gastric cancer in the world (1). Clinically, gastric cancer rarely presents with noticeable early signs and symptoms in the early stage; thus, most patients are diagnosed at advanced stages (2). To date, various treatment options, such as surgery, radiotherapy, and chemotherapy, are routinely used to manage gastric cancer patients, but the overall 5-year patient survival rate still remains at only $26 \%(3,4)$. The significant failure of the treatment and the poor survival rate are due to diagnosis at the later stages, which make surgical resection impossible; therefore, innovative treatment strategies and approaches to early gastric cancer diagnosis could significantly improve survival and treatment outcome of this disease.

It has been well documented that angiogenesis plays an important role in growth and metastasis of gastric cancer $(5,6)$. Thus, anti-angiogenesis has been used as a potential and promising strategy in gastric cancer treatment by developing anti-angiogenesis drugs in clinical trials against gastric cancer (6-8). A comprehensive understanding of angiogenesis mechanisms responsible for gastric cancer progression could lead to novel treatment approaches. To this end, our research has focused on the crucial molecules involved in gastric cancer angiogenesis.

Protease-activated receptors (PARs) are a recently described subfamily of G-protein-coupled receptors with seven transmembrane-spanning domains and are comprised of four proteins, i.e., PAR-1, PAR-2, PAR-3, and PAR-4 (9). Among the four receptors, PAR-2 is mainly activated by trypsin and other trypsin-like serine proteases through cleavage of the extracellular N-terminal domain, which in turn enables the $\mathrm{N}$-terminus of the protein to bind to the receptor itself as a tethered ligand to activate G-protein-coupled signal transduction pathways (10). PAR-2 is widely expressed in a 
variety of tissues, with a high expression level in the gastrointestinal tract, where physiological trypsin is highly expressed (11). Functionally, PAR-2 has been implicated in inflammation, pain, tissue injury, as well as in the regulation of gastrointestinal functions and diseases (12). Furthermore, PAR-2 protein is also highly expressed in various cancers, such as breast, colorectal, pancreatic, gastric, gallbladder, kidney, lung, uterine, cervical cancer and melanoma, and glioblastoma $(13,14)$.

Recently, increasing attention has focused on the role of PAR-2 in angiogenesis (15). For example, PAR-2 activation in vascular endothelial cells was able to stimulate angiogenesis during tissue repair and promote neovascularization of the retina $(15,16)$. PAR-2 activation also was shown to induce proliferation of endothelial cells, enhance production of proangiogenesis cytokines (such as vascular endothelial growth factor, namely VEGF), and upregulate expression of cyclooxygenase-2 (COX-2) protein in human endothelial cells and other types of cells (17-21). In gastric cancer (22), overexpression of PAR-2 protein could be the key inducer of angiogenesis. However, the underlying molecular mechanism responsible for PAR-2 action has yet to be determined. In the present study, we hypothesized that PAR-2 activation by trypsin contributes to gastric cancer angiogenesis, which may be through upregulation of VEGF and COX-2 expression.

\section{Materials and methods}

Cell lines and culture. A well-differentiated human tubular gastric adenocarcinoma MKN-28 cell line was kindly provided by Professor Fang-Dong Men of The Institute of Oncology, China Medical University, Shenyang, China. The human lung adenocarcinoma A549 cell line was purchased from the Chinese Academy of Sciences, Shanghai, China. These cell lines were cultured in RPMI-1640 medium (GibcoLife Technologies, Grand Island, NY, USA) supplemented with $10 \%$ fetal bovine serum (FBS; Gibco) at $37^{\circ} \mathrm{C}$ in a humidified atmosphere containing $95 \%$ air and $5 \% \mathrm{CO}_{2}$. Cells were seeded at $1 \times 10^{6}$ cells per well in 6-well plates for reverse transcription polymerase chain reaction (RT-PCR) and western blot analysis, or at $5 \times 10^{5}$ cells per well in 12-well plates for ELISA. In each experiment, MKN-28 cells were first deprived of FBS for $2 \mathrm{~h}$ and then treated with trypsin, SB20358 (a p38 MAP kinase inhibitor), or PD98059 (a specific inhibitor to block ERK1/2 phosphorylation). Trypsin was purchased from Amresco (Solon, OH, USA), and SB20358 and PD98059 were from Sigma Chemical Co. (St. Louis, MO, USA).

RNA isolation and RT-PCR. Total RNA was isolated from the cultured cells using the TRIzol reagent (Invitrogen, Carlsbad, CA, USA) according to the manufacturer's protocol. The concentration and purity of the freshly isolated RNA were measured by the optical densities at 260 and $280 \mathrm{~nm}$ using a Beckman Coulter DU 530 spectrophotometer. The RNA was then reverse transcribed into cDNA using a PrimeScript ${ }^{\mathrm{TM}}$ RT Reagent kit (Takara, Dalian, China) according to the manufacturer's instructions. Next, PCR amplification was performed using a Takara PCR amplification kit (Takara) in a total volume of $25 \mu \mathrm{l}$ containing $2 \mu \mathrm{l}$ of cDNA $(0.5 \mu \mathrm{g}), 200 \mu \mathrm{M}$ each dNTP, 1.25 units of Taq polymerase, and $0.2 \mu \mathrm{M}$ each primer (Takara). The PCR was set at $94^{\circ} \mathrm{C}$ for $3 \mathrm{~min}$, followed by 30 cycles of denaturation at $94^{\circ} \mathrm{C}$ for $30 \mathrm{sec}$, annealing at $55^{\circ} \mathrm{C}$ for $30 \mathrm{sec}$, and extension at $72^{\circ} \mathrm{C}$ for $30 \mathrm{sec}$, and a final extension at $72^{\circ} \mathrm{C}$ for $10 \mathrm{~min}$. The amplified PCR products were then separated by agarose gel electrophoresis and visualized by ethidium bromide staining. The primers used for detection of PAR-2 mRNA were 5'-GGC CAA TCT GGC CTT GGC TGA C-3' (sense) and 5'-GGG CAG GAA TGA AGA TGG TCT GC-3' (antisense), and for $\beta$-actin they were 5'-GCC AAC CGT GAA AAG ATG-3' (sense) and 5'-CCA GGA TAG AGC CAC CAA T-3' (antisense).

Real-time RT-PCR. To quantify PAR-2 mRNA levels, realtime RT-PCR (qRT-PCR) was performed with the LightCycler thermal cycling system (Roche Diagnostics Corp., Indianapolis, IN, USA) using a SYBR ${ }^{\circledR}$ Premix Ex Taq ${ }^{\mathrm{TM}}$ II (Perfect realtime) kit (Takara) as described by the manufacturer. Briefly, the total qPCR volume was $20 \mu \mathrm{l}$, which contained $2 \mu \mathrm{l}$ of cDNA template (100 ng), $10 \mu \mathrm{l}$ of 2 X SYBR Premix Ex Taq II, $0.8 \mu \mathrm{l}$ of primers $\left(10 \mu \mathrm{M}\right.$ each), and $6.4 \mu \mathrm{l}$ of $\mathrm{ddH}_{2} \mathrm{O}$. After an initial denaturation at $95^{\circ} \mathrm{C}$ for $3 \mathrm{~min}, \mathrm{PCR}$ was performed for 40 cycles of $95^{\circ} \mathrm{C}$ for $30 \mathrm{sec}$ and $60^{\circ} \mathrm{C}$ for $30 \mathrm{sec}$. The primer sequences for human VEGF were 5'-TGA CGG ACA GAC AGA CAG ACA CC-3' (sense) and 5'-AGA ACA GCC CAG AAG TTG GAC GA-3' (antisense), for COX-2 they were 5'-TCA CAG GCT TCC ATT GAC CAG-3' (sense) and 5'-CCG AGG CTT TTC TAC CAG A-3' (antisense), and for $\beta$-actin they were 5'-TCA TCA CCA TTG GCA ATG AG-3' (sense) and 5'-CAC TGT GTT GGC GTA CAG GT-3' (antisense). All primers were synthesized by Takara. The qPCR data were analyzed by using the Roche Molecular Biochemicals LightCycler software (version 3.5). Specificity of the amplification reactions was confirmed by analyzing their corresponding melting curves. The relative expression of each gene was normalized with the $\beta$-actin control and then estimated as values of $2^{-\Delta \Delta C t}$.

Protein extraction and western blotting. Total cellular protein was extracted from the cultured tumor cells with ice-cold lysis buffer containing $50 \mathrm{mM}$ Tris/ $\mathrm{HCl}(\mathrm{pH} 7.5), 150 \mathrm{mM} \mathrm{NaCl}$, $10 \%$ glycerol, $10 \mathrm{mM} \mathrm{NaF}, 1 \mathrm{mM} \mathrm{Na} 3$ vanadate, $0.2 \mathrm{mM}$ phenylmethylsulfonyl fluoride (PMSF), $10 \mu \mathrm{g} / \mathrm{ml}$ aprotinin (pH 7.3), $10 \mu \mathrm{g} / \mathrm{ml}$ leupeptin, 0.1\% SDS, $1 \mathrm{mM}$ EGTA, $1 \mathrm{mM}$ EDTA, $0.5 \%$ deoxysodium cholate, and 1\% NP-40 for $15 \mathrm{~min}$, followed by centrifugation at $21,000 \mathrm{x}$ for $15 \mathrm{~min}$ at $4^{\circ} \mathrm{C}$. The concentrations of these protein samples were determined using a BCA Protein Assay kit (Bio-Rad Laboratories, Hercules, CA, USA) standardized to bovine serum albumin (BSA) according to the manufacturer's protocol.

The protein samples (50 $\mu \mathrm{g}$ for each lane) were resolved by electrophoresis in 7.5 or $12.5 \%$ SDS-PAGE precast gels (Bio-Rad). Protein samples were then electro-transferred onto nitrocellulose membranes. The membranes were incubated in $5 \%$ (w/v) non-fat dry milk in $20 \mathrm{mM}$ Tris-buffered saline with $0.1 \%$ Tween (TBS-T) for $2 \mathrm{~h}$ at room temperature and then with the primary antibodies overnight at $4^{\circ} \mathrm{C}$. These primary antibodies were human PAR-2 (sc-8205, 1:1000), VEGF (sc-7269, 1:1000), COX-2 (sc-7951, 1:1000), ERK1/2 (sc-93, 1:2000), p38 (sc-7972, 1:2000), phosphorylated ERK1/2 (p-ERK1/2), phosphorylated p38 (p-p38), the phospho-specific antibodies targeting p-ERK1/2 (Tyr 204) (sc-7383, 1:1000), p-p38 (Tyr182) (sc-7973, 1:2000), or $\beta$-actin (sc-1615, 1:1000), all of which were 
A

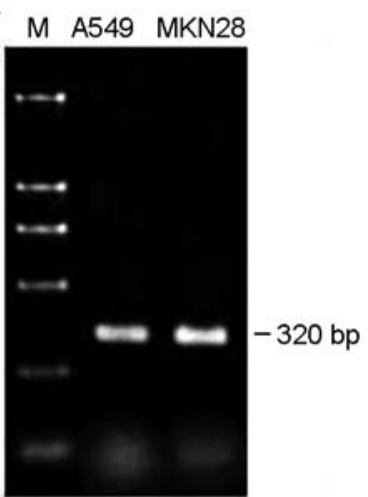

PAR-2

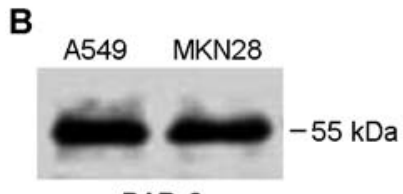

PAR-2

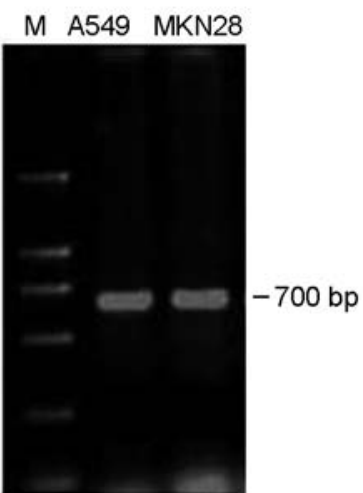

$\beta$-actin

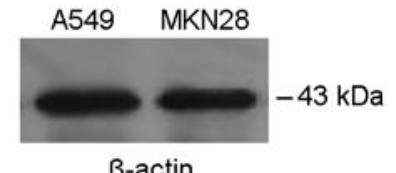

Figure 1. Expression of PAR-2 in gastric cancer cells. (A) RT-PCR: Gastric cancer MKN28 cells were grown and subjected to RT-PCR analysis of PAR-2 mRNA levels. Lung cancer A549 cells were used as the positive control. (B) Western blotting: Gastric cancer MKN28 cells were grown and subjected to western blot analysis of PAR-2 protein levels. Lung cancer A549 cells were used as the positive control.

from Santa Cruz Biotechnology Inc. (Santa Cruz, CA, USA). The next day, the membranes were washed three times with TBS-T and then incubated with the HRP-conjugated antirabbit, anti-mouse, or anti-goat secondary antibodies (Santa Cruz Biotechnology Inc.) at a dilution of 1:2000 for $1 \mathrm{~h}$ at room temperature. The membranes were washed extensively with TBS-T three times and positive signals were detected by using the enhanced chemiluminescence detection system (Beyotime, China) and exposed to X-ray film.

ELISA analysis. The levels of VEGF in the conditioned cell culture media were determined by using ELISA. Briefly, gastric cancer MNK28 cells were seeded at $5 \times 10^{5}$ cells per well into 12 -well plates and grown to reach a confluence of $60-70 \%$. Next, the cells were washed three times with phosphate-buffered saline (PBS), and the culture medium was replaced with serum-free medium and treated with increased concentrations of trypsin (0-100 nM; Amresco) for $6 \mathrm{~h}$, or treated with $10 \mathrm{nM}$ trypsin for up to $24 \mathrm{~h}$. At the end of the experiments, the conditioned cell culture medium was harvested and centrifuged for ELISA. A commercially available sandwich ELISA kit (Jinmei Biotechnology Co., Ltd., Shenzhen, China) was used to assess VEGF concentration in the supernatant of the conditioned growth medium according to the manufacturer's instructions. The data were normalized to the kit controls and the number of producing cells and then expressed as pg of VEGF protein per $10^{6}$ cells.

Statistical analysis. All experiments were performed in triplicate and repeated at least three times. Data are expressed as means \pm standard deviation (SD). The Student's t-test was used to compare the means of two groups. $\mathrm{P}<0.05$ was considered statistically significant. All analyses were performed using SPSS 10.0 statistical packages (SPSS Inc., Chicago, IL, USA).

\section{Results}

Expression of PAR-2 in gastric cancer MKN28 cells. Expression of PAR-2 mRNA and protein was determined in MKN28 gastric cancer cells by using RT-PCR and western blot, respectively. As shown in Fig. 1A, a 320-bp PAR-2 target band was amplified by RT-PCR, indicating that MKE28 expressed PAR- 2 mRNA. Moreover, western blot data showed that the anti-PAR-2 antibody can specifically detect a 55-kDa PAR-2 target band (Fig. 1B). Lung cancer A549 cells, highly expressing PAR-2, were used as a positive control.

Effects of trypsin-activated PAR-2 on enhanced expression of VEGF and COX-2 in gastric cancer cells. Next, we determined different gene expressions after gastric cancer cells were treated with trypsin at different doses or time points. We found that different treatment doses of trypsin for $6 \mathrm{~h}$ were able to activate PAR-2 expression (Fig. 2A) and in turn to upregulate VEGF and COX-2 expression in MKN28 cells. As shown in Fig. 2A, with increased concentrations of trypsin up to $100 \mathrm{nM}$, expression levels of VEGF and COX-2 mRNA were increased in a dose-dependent manner, e.g., $10 \mathrm{nM}$ trypsin induced levels of VEGF and COX-2 mRNA by 7.7-fold and 8.3-fold, respectively, compared to their corresponding basal levels $(\mathrm{P}<0.05)$. Similar data were confirmed by using western blotting (Fig. 2B). Furthermore, VEGF protein expression in the conditioned media was also induced in a dose-dependent manner (Fig. 2C). Particularly, $10 \mathrm{nM}$ trypsin treatment of MKN28 cells increased expression of VEGF protein to $81.7 \mathrm{pg} / \mathrm{ml}$ in the conditioned growth medium, while $100 \mathrm{nM}$ trypsin treatment upregulated VEGF levels to $101.7 \mathrm{pg} / \mathrm{ml}(\mathrm{P}<0.05)$. Taking all the findings into consideration, a concentration of $10 \mathrm{nM}$ trypsin was used for further experiments.

Furthermore, induction of VEGF and COX-2 expression by activated PAR-2 at different time points was also analyzed in MKN28 cells. As shown in Fig. 3A, up to $10 \mathrm{~h}$ of treatment of MKN28 cells with $10 \mathrm{nM}$ trypsin upregulated both mRNA and protein levels of VEGF and COX-2 expression in a time-dependent manner. A 24-h treatment of tumor cells with trypsin induced expression of VEGF and COX-2 to the peak mRNA levels, whereas the peak levels of their protein expression were reached after a 12-h treatment, although there was no statistical difference in expression of VEGF protein after 6,12 , or $24 \mathrm{~h}$ of treatment (Fig. 3B). The maximum COX-2 protein expression was found at $24 \mathrm{~h}$ of treatment, without statistical difference between 12 and $24 \mathrm{~h}$ (Fig. 3B). The VEGF concentration in the conditioned media was also time-dependent (Fig. 3C).

Effects of trypsin-activated PAR-2 on induction of ERKI/2 and p38 MAP kinase phosphorylation. To determine whether the MAP kinase signaling pathway participates in the upregulation of VEGF and COX-2 expression, we assessed the total and phosphorylated ERK1/2 and p38 MAP kinase proteins after trypsin-induced PAR-2 activation in MKN28 cells. As shown in Fig. 4, expression levels of the total ERK1/2 protein showed no significant changes from 0 to $60 \mathrm{~min}$, whereas phosphorylated 
A

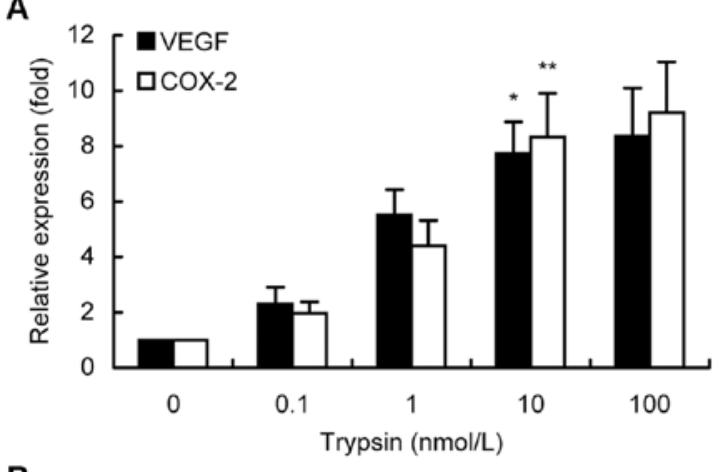

B

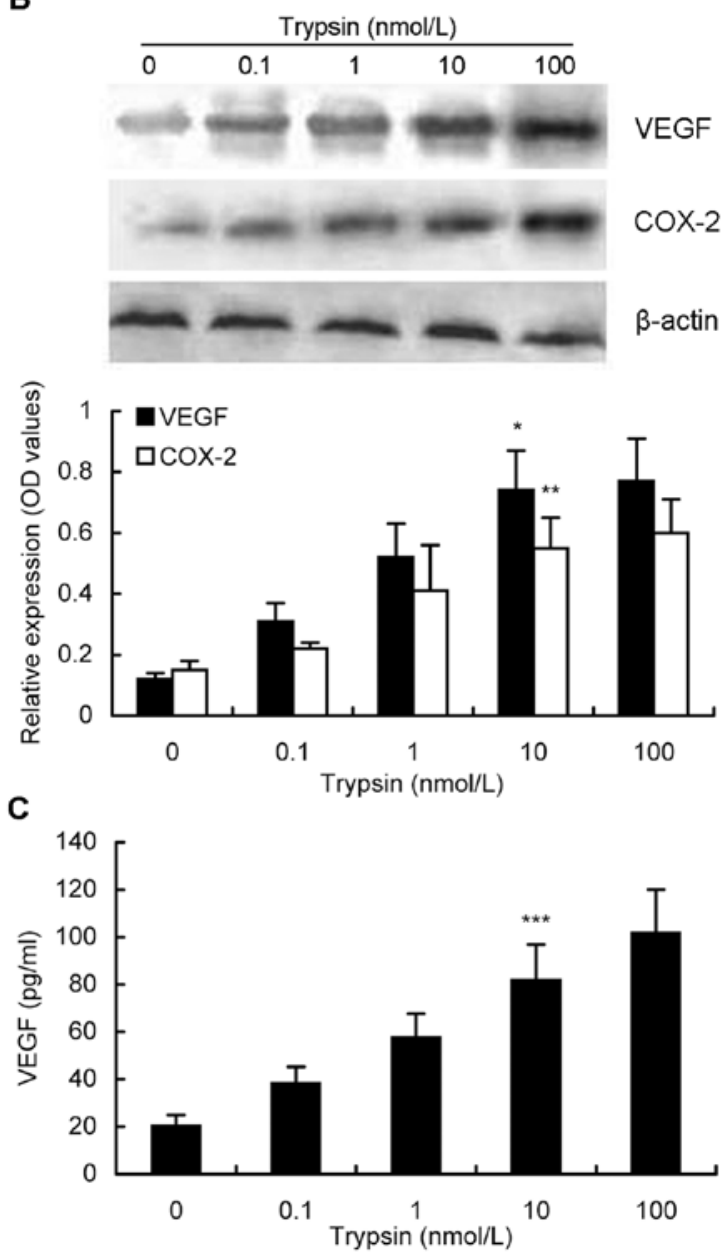

Figure 2. Effects of trypsin-activated PAR-2 on the expression of VEGF and COX-2 mRNA and protein in a dose-dependent manner. (A) qRT-PCR: Gastric cancer MKN28 cells were grown and treated with $\leq 100 \mathrm{nM}$ trypsin for $6 \mathrm{~h}$ and then subjected to qRT-PCR analysis of gene expression. The graph shows quantitative RT-PCR data. ${ }^{*} \mathrm{P}>0.05 ;{ }^{* *} \mathrm{P}>0.05$. (B) Western blotting: The same trypsin-treated MKN28 cells were subjected to western blot analysis. ${ }^{*} \mathrm{P}>0.05 ;{ }^{* * *} \mathrm{P}>0.05$. (C) ELISA analysis: The conditioned cell growth medium from the same trypsin-treated MKN28 cells was subjected to ELISA analysis of VEGF protein concentration. ${ }^{* * * *} \mathrm{P}<0.05$.

ERK1/2 protein was induced by trypsin-induced PAR-2 activation, which peaked at $15 \mathrm{~min}$ and returned back to the basal level at $60 \mathrm{~min}$. A similar time-dependent manner for p38 MAP kinase phosphorylation was also noted, i.e., trypsin-induced PAR-2 activation upregulated significant and sustained phosphorylation of p38 MAP kinase that began at $5 \mathrm{~min}$, reached the maximum at $30 \mathrm{~min}$ with nearly a 4 -fold increase compared to
A

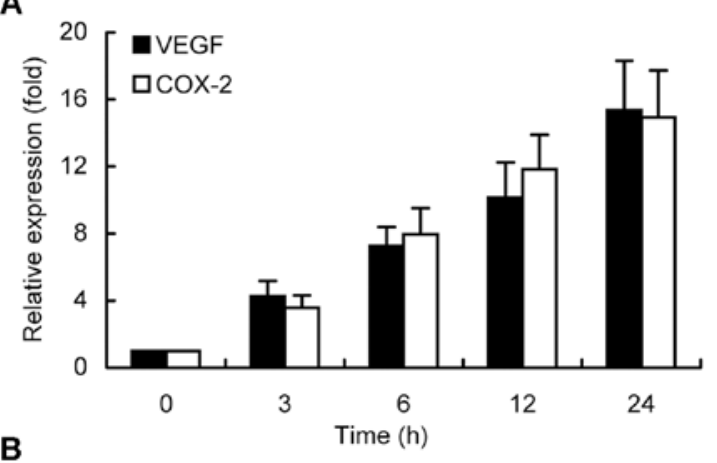

B
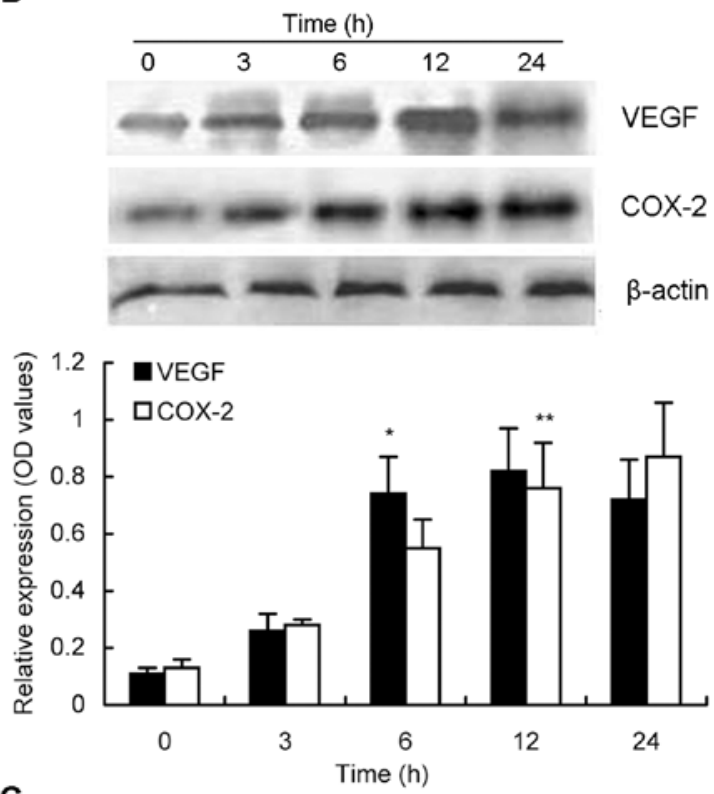

C

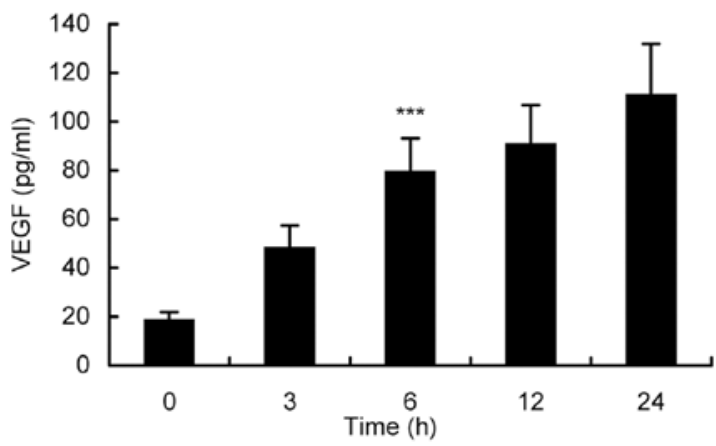

Figure 3. Effects of trypsin-activated PAR-2 on the expression of VEGF and COX-2 mRNA and protein in a time-dependent manner. (A) qRT-PCR: Gastric cancer MKN28 cells were grown and treated with $10 \mathrm{nM}$ trypsin up to $24 \mathrm{~h}$ and then subjected to qRT-PCR analysis of gene expression. The graph summarizes the qRT-PCR data. (B) Western blotting: The same trypsin-treated MKN28 cells were subjected to western blot analysis. ${ }^{*} \mathrm{P}>0.05 ;{ }^{* *} \mathrm{P}>0.05$. (C) ELISA analysis: The conditioned cell growth medium from the same trypsin-treated MKN28 cells was subjected to ELISA analysis of VEGF protein concentration. ${ }^{* * * *} \mathrm{P}<0.05$.

the untreated controls, and then returned to the basal level after $60 \mathrm{~min}$.

ERK1/2 and p38 inhibitors antagonize the effects of trypsinactivated PAR-2 on induction of VEGF and COX-2 expression. Next, we determined the role of the MAP kinase signaling pathway in mediating the effects of trypsin-activated PAR-2 on the induction of VEGF and COX-2 expression by pretreating 


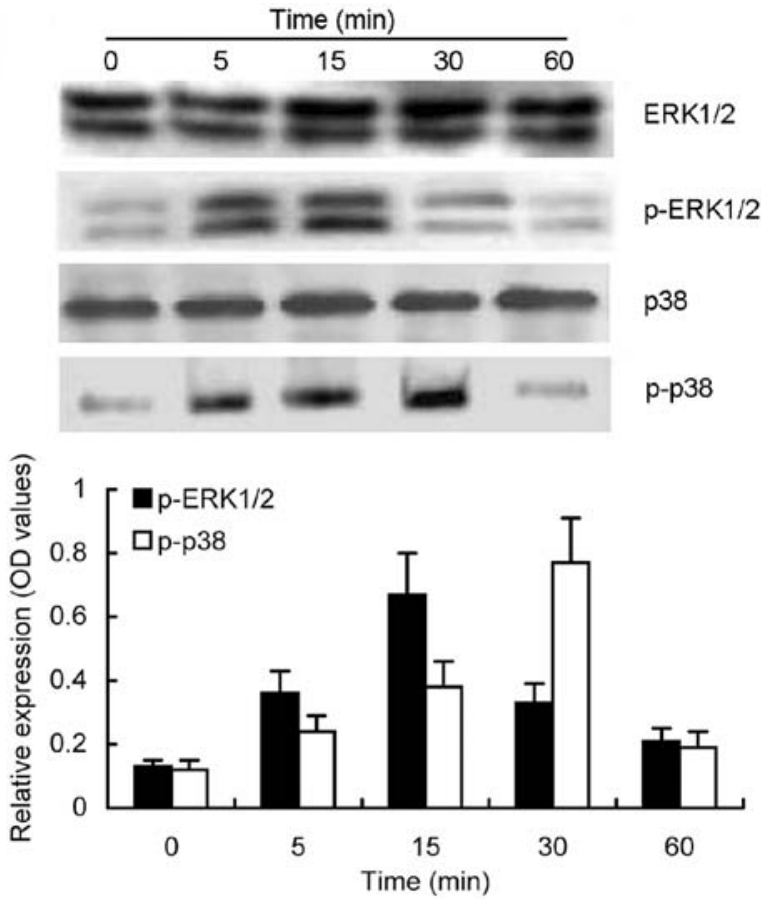

Figure 4. Effects of trypsin-activated PAR-2 on the induction of ERK1/2 and p38 MAP kinase phosphorylation. Gastric cancer MKN28 cells were grown and treated with $10 \mathrm{nM}$ trypsin up to $24 \mathrm{~h}$ and then subjected to western blot analysis.

MKN28 cells with specific ERK1/2 and p38 MAP kinase inhibitors (25 $\mu \mathrm{M}$ PD98059 or $20 \mu \mathrm{M}$ SB203580, respectively) $1 \mathrm{~h}$ prior to PAR-2 activation with $10 \mathrm{nM}$ trypsin for $6 \mathrm{~h}$. We found that compared to the PBS control, treatment with $10 \mathrm{nM}$ trypsin resulted in 7.0- and 7.5-fold induction of VEGF and COX-2 mRNA, respectively, whereas these increases in VEGF and COX-2 mRNA and protein levels were completely blocked by treatment with PD98059 or SB203580 in gastric cancer MKN28 cells (Fig. 5). However, there was no significant difference in VEGF and COX-2 expression between the control cells and PD98059 or SB203580-treated tumor cells alone (Fig. 5). The data suggested that the role of PAR-2 was mediated by the MAP kinase signaling pathway to upregulate expression of VEGF and COX-2 mRNA and protein.

\section{Discussion}

In this study, we chose gastric cancer cells to demonstrate that PAR-2 activation was able to upregulate expression of proangiogenesis genes and defined the underlying molecular pathway. Our data showed that trypsin-activated PAR-2 induced expression of VEGF and COX-2 in gastric cancer cells in a dose- and time-dependent manner. The ability of PAR-2 to induce VEGF and COX-2 expression was mediated by ERK1/2 and p38 gene signaling, i.e., pretreatment with ERK1/2 and p38 inhibitors blocked the effects of trypsin-activated PAR-2 on the induction of VEGF and COX-2 expression. Since angiogenesis plays an important role in gastric cancer development and progression, this study might provide a novel anti-angiogenesis target for future treatment of gastric cancer patients.

PAR-2 is a member of the protease-activated receptor family. Various proteases can cleave PAR-2 within the extracellular
A

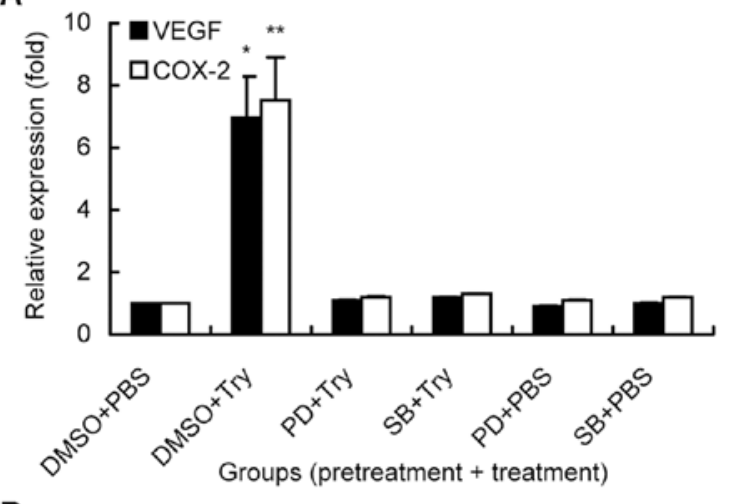

B
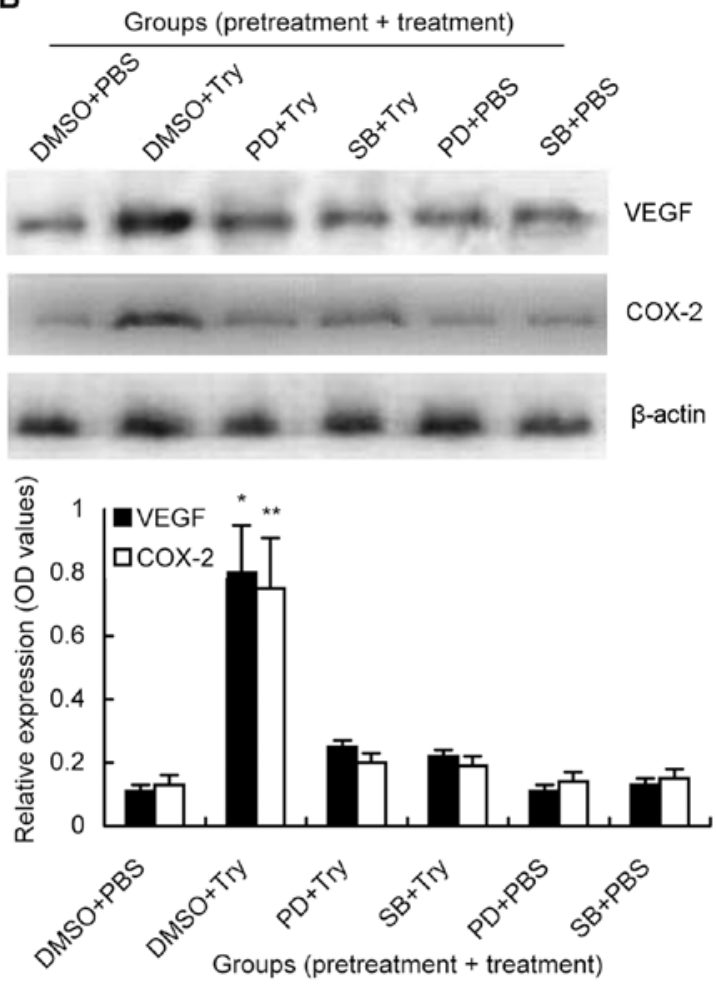

Figure 5. ERK1/2 and p38 inhibitors antagonized the effects of trypsinactivated PAR-2 on the expression of VEGF and COX-2. (A) qRT-PCR: Gastric cancer MKN28 cells were grown and treated with ERK1/2 and p38 inhibitors ( $25 \mu \mathrm{M}$ PD98059 or $20 \mu \mathrm{M}$ SB203580, respectively) $1 \mathrm{~h}$ before $10 \mathrm{nM}$ trypsin treatment for $6 \mathrm{~h}$ and then subjected to RT-PCR or qRT-PCR analysis of gene expression. ${ }^{*} \mathrm{P}<0.05 ;{ }^{*} \mathrm{P}<0.05$. (B) Western blotting: The same trypsin-treated MKN28 cells were subjected to western blot analysis. ${ }^{*} \mathrm{P}<0.05 ;{ }^{* *} \mathrm{P}<0.05$.

$\mathrm{N}$-terminal domain to expose a tethered ligand that binds to and activates the cleaved receptor. Among these different proteases, trypsin is a potent PAR-2 activator that cleaves and triggers PAR-2 activation, although trypsin was traditionally regarded as an enzyme with the principal function of degrading dietary proteins (23). A wide expression of PAR-2 has been observed in the gastrointestinal tract in physiological conditions and malignant gastrointestinal diseases (24-26). Trypsin, the most prominent ligand of PAR-2, is not only maintained at a higher concentration in the gastrointestinal tract naturally, but also can be secreted by a few types of cancer cells derived from the gastrointestinal tract by an autocrine mechanism (27-29).

Accumulating evidence has demonstrated that PAR-2 is involved in the development and progression of human 
cancers. For example, PAR-2 overexpression has been associated with the depth of tumor invasion, lymphatic involvement, early metastasis, and poor prognosis of gastric cancer and other types of cancer $(22,26,30,31)$. Activated PAR-2 enhanced the growth of gastric cancer cells via transactivation of epidermal growth factor receptor (EGFR) (24). Activated PAR-2 also promoted the proliferation of colon cancer cells with a similar mechanism (25). In addition to the mutagenic function, a potential proangiogenesis effect of PAR-2 has been confirmed in breast cancer and uterine endometrial cancer $(19,30)$. Particularly, in human breast cancer cells, activation of PAR-2 with an agonist peptide, trypsin, or FVIIa resulted in a robust increase in expression of VEGF mRNA and protein, the most prominent inducer of angiogenesis (19). Additionally, in human bile duct cancer cells, PAR-2 agonist peptide activated expression of COX-2 mRNA and protein, and the latter is responsible for prostaglandin biosynthesis, which also contributes to tumor angiogenesis (32). Moreover, COX-2 can increase VEGF production, and a link between COX-2, PGE2, and VEGF was proposed in AGS gastric cancer cells $(33,34)$. Therefore, VEGF and COX-2 were presumed to mediate the proangiogenesis capacity of PAR-2 in gastric cancer.

In the present study, we first determined the effect of PAR-2 activation on the intracellular expression of VEGF and COX-2 in MKN28 gastric cancer cells and secreted VEGF in the conditioned medium. Our data revealed that trypsin-activated PAR-2 was able to upregulate the expression of COX-2 mRNA and protein in a dose- and time-dependent manner. Thereafter, we demonstrated that trypsin-activated PAR-2 could also increase the expression of VEGF mRNA and protein in gastric cancer cells. These data demonstrated and confirmed the effects of PAR-2 on increasing the expression of angiogenesisrelated genes in gastric cancer cells.

Furthermore, previous studies have reported that PAR-2 activated by trypsin modulated the downstream signal transduction pathway through the activation of the MAP kinase cascade $(19,32,35,36)$. In this study, we showed that trypsinactivated PAR-2 increased the phosphorylation of ERK1/2 and p38 MAP kinase. It is to be determined whether the MAP kinase cascade is the upstream gene pathway that regulates the expression of VEGF and COX-2. As shown in Fig. 5, at both the mRNA and protein level, PD98059 (ERK1/2 inhibitor) and SB203580 (p38 MAP kinase inhibitor) dramatically blocked the expression of VEGF and COX-2 induced by trypsin. These data indicate that PAR-2 induced VEGF and COX-2 expression is through the MAP kinase pathway. However, a striking difference has been noted in the mechanism responsible for activation of the MAP kinase signal transduction pathway by PAR-2 among a variety of cells and tissues. For example, trypsin-activated PAR-2 was able to strongly activate ERK1/2 protein but weakly activate p38 by trypsin-activated PAR-2 in rat aortic smooth-muscle cells with both endogenous and exogenous PAR-2 expression $(35,37,38)$. In contrast, in human keratinocytes with PAR-2 overexpression, trypsin-activated PAR-2 strongly induced p38 MAP kinase activation, but weakly induced ERK1/2 activation (39).

Additionally, ERK1/2, p38, and JNK MAP kinases also could simultaneously be involved in the signal transduction following trypsin-induced PAR-2 activation, with indepen- dence or interdependence among them $(40,41)$. In this study, we found that both ERK1/2 and p38 MAP kinase were involved in trypsin-activated PAR-2 upregulation of COX-2 and VEGF expression in MKN28 cells. Our current data were consistent with findings in dental pulp cells and intestinal epithelial cells $(42,43)$. Furthermore, although the downstream signaling of PAR-2 in MKN28 cells also involved these two MAP kinases (i.e., ERK1/2 and p38 MAP kinase), inhibition of either one did eliminate the PAR-2-mediated upregulation of VEGF and COX-2 expression. Each of these MAP kinases appeared to modulate expression of VEGF and COX-2 independently.

It is generally believed that VEGF plays a key role in tumor angiogenesis and VEGF production is regulated by the tumor microenvironment. Hypoxia is known to be a potent inducer of VEGF, which then contributes to angiogenesis in many types of cancer (44). However, in the present study, the MKN28 cells were cultured with sufficient oxygen and a greatly enhanced expression of VEGF still could be observed. The data suggest that gastric cancer cells continue to produce VEGF under normal oxygen levels through a PAR-2-dependent MAP kinase pathway. Therefore, trypsin-PAR-2-MAP kinaseCOX-2/VEGF signaling might present a novel mechanism of angiogenesis in gastric cancer, and further investigations are required. More importantly, a few PAR-2 antagonists and inhibitors have been described recently and PAR-2 might serve as a novel target for anti-angiogenesis therapy for patients with gastric cancer (45).

\section{Acknowledgements}

We thank Medjaden Bioscience Limited for assisting in the preparation of this manuscript.

\section{References}

1. Ferlay J, Shin H, Bray F, Forman D, Mathers C and Parkin D: GLOBOCAN 2008, Cancer Incidence and Mortality Worldwide: IARC CancerBase no. 10. International Agency for Research on Cancer: Lyon. http://globocan.iarc.fr. Accessed Nov. 19, 2010.

2. Koh T and Wang T (eds): Tumors of the Stomach. Saunders, Philadelphia, PA, 2002.

3. Japanese Gastric Cancer Association: Japanese Gastric Cancer Treatment Guidelines 2010 (version 3). Gastric Cancer 14: 113-123, 2011.

4. Siegel R, Ward E, Brawley O and Jemal A: Cancer statistics, 2011: the impact of eliminating socioeconomic and racial disparities on premature cancer deaths. CA Cancer J Clin 61: 212-236, 2011.

5. Kitadai Y: Angiogenesis and lymphangiogenesis of gastric cancer. J Oncol 2010: 468725, 2010.

6. Kakeji Y, Maehara Y, Sumiyoshi Y, Oda S and Emi Y: Angiogenesis as a target for gastric cancer. Surgery 131: S48-S54, 2002.

7. Iwasaki J and Nihira S: Anti-angiogenic therapy against gastrointestinal tract cancers. Jpn J Clin Oncol 39: 543-551, 2009.

8. Okines AF, Reynolds AR and Cunningham D: Targeting angiogenesis in esophagogastric adenocarcinoma. Oncologist 16: 844-858, 2011.

9. Trejo J: Protease-activated receptors: new concepts in regulation of $\mathrm{G}$ protein-coupled receptor signaling and trafficking. J Pharmacol Exp Ther 307: 437-442, 2003.

10. Cottrell GS, Amadesi S, Schmidlin F and Bunnett N: Proteaseactivated receptor 2: activation, signalling and function. Biochem Soc Trans 31: 1191-1197, 2003.

11. Vergnolle N: Review article: proteinase-activated receptors - novel signals for gastrointestinal pathophysiology. Aliment Pharmacol Ther 14: 257-266, 2000.

12. Ossovskaya VS and Bunnett NW: Protease-activated receptors: contribution to physiology and disease. Physiol Rev 84: 579-621, 2004. 
13. Schaffner F and Ruf W: Tissue factor and protease-activated receptor signaling in cancer. Semin Thromb Hemost 34: 147-153, 2008.

14. Elste AP and Petersen I: Expression of proteinase-activated receptor 1-4 (PAR 1-4) in human cancer. J Mol Histol 41: 89-99, 2010.

15. Milia AF, Salis MB, Stacca T, et al: Protease-activated receptor-2 stimulates angiogenesis and accelerates hemodynamic recovery in a mouse model of hindlimb ischemia. Circ Res 91: 346-352, 2002.

16. Belting M, Dorrell MI, Sandgren S, et al: Regulation of angiogenesis by tissue factor cytoplasmic domain signaling. Nat Med 10: 502-509, 2004

17. Mirza H, Yatsula V and Bahou WF: The proteinase activated receptor-2 (PAR-2) mediates mitogenic responses in human vascular endothelial cells. J Clin Invest 97: 1705-1714, 1996.

18. Chen J, Bierhaus A, Schiekofer S, et al: Tissue factor - a receptor involved in the control of cellular properties, including angiogenesis. Thromb Haemost 86: 334-345, 2001.

19. Liu Y and Mueller BM: Protease-activated receptor-2 regulates vascular endothelial growth factor expression in MDA-MB-231 cells via MAPK pathways. Biochem Biophys Res Commun 344: 1263-1270, 2006.

20. Seymour ML, Binion DG, Compton SJ, Hollenberg MD and MacNaughton WK: Expression of proteinase-activated receptor 2 on human primary gastrointestinal myofibroblasts and stimulation of prostaglandin synthesis. Can J Physiol Pharmacol 83: 605-616, 2005.

21. Syeda F, Grosjean J, Houliston RA, et al: Cyclooxygenase-2 induction and prostacyclin release by protease-activated receptors in endothelial cells require cooperation between mitogen-activated protein kinase and NF-kappaB pathways. J Biol Chem 281: 11792-11804, 2006.

22. Fujimoto D, Hirono Y, Goi T, Katayama K, Hirose K and Yamaguchi A: Expression of protease activated receptor-2 (PAR-2) in gastric cancer. J Surg Oncol 93: 139-144, 2006.

23. Dery O, Corvera CU, Steinhoff M and Bunnett NW: Proteinaseactivated receptors: novel mechanisms of signaling by serine proteases. Am J Physiol 274: C1429-C1452, 1998.

24. Caruso R, Pallone F, Fina D, et al: Protease-activated receptor-2 activation in gastric cancer cells promotes epidermal growth factor receptor trans-activation and proliferation. Am J Pathol 169: 268-278, 2006

25. Darmoul D, Gratio V, Devaud H and Laburthe M: Proteaseactivated receptor 2 in colon cancer: trypsin-induced MAPK phosphorylation and cell proliferation are mediated by epidermal growth factor receptor transactivation. J Biol Chem 279 : 20927-20934, 2004

26. Chang JH, Park JM, Kim SW, Jung CK, Kang WK and Oh ST: Expression of protease activated receptor-2 in human colorectal cancer and its association with tumor progression. Dis Colon Rectum 53: 1202-1208, 2010

27. Kong W, McConalogue K, Khitin LM, et al: Luminal trypsin may regulate enterocytes through proteinase-activated receptor 2. Proc Natl Acad Sci USA 94: 8884-8889, 1997

28. Ichikawa Y, Koshikawa N, Hasegawa S, et al: Marked increase of trypsin(ogen) in serum of linitis plastica (gastric cancer, borrmann 4) patients. Clin Cancer Res 6: 1385-1388, 2000.

29. Nakanuma S, Tajima H, Okamoto K, et al: Tumor-derived trypsin enhances proliferation of intrahepatic cholangiocarcinoma cells by activating protease-activated receptor-2. Int $\mathrm{J}$ Oncol 36: 793-800, 2010
30. Jahan I, Fujimoto J, Alam SM, Sato E, Sakaguchi H and Tamaya T: Expression of protease activated receptor-2 related to angiogenesis in tumor advancement of uterine endometrial cancers. Oncol Rep 17: 345-350, 2007.

31. Jahan I, Fujimoto J, Alam SM, Sato E, Sakaguchi H and Tamaya T: Role of protease activated receptor- 2 in tumor advancement of ovarian cancers. Ann Oncol 18: 1506-1512, 2007.

32. Eguchi H, Iwaki K, Shibata K, Ogawa T, Ohta M and Kitano S: Protease-activated receptor-2 regulates cyclooxygenase-2 expression in human bile duct cancer via the pathways of mitogen-activated protein kinases and nuclear factor kappa B. J Hepatobiliary Pancreat Sci 18: 147-153, 2011.

33. Joo YE, Rew JS, Seo YH, et al: Cyclooxygenase-2 overexpression correlates with vascular endothelial growth factor expression and tumor angiogenesis in gastric cancer. J Clin Gastroenterol 37: 28-33, 2003.

34. Huang SP, Wu MS, Shun CT, et al: Cyclooxygenase-2 increases hypoxia-inducible factor-1 and vascular endothelial growth factor to promote angiogenesis in gastric carcinoma. J Biomed Sci 12: 229-241, 2005.

35. Belham CM, Tate RJ, Scott PH, et al: Trypsin stimulates proteinase-activated receptor-2-dependent and -independent activation of mitogen-activated protein kinases. Biochem J 320: 939-946, 1996

36. Yang XP, Li Y, Wang Y and Wang P: Beta-Tryptase up-regulates vascular endothelial growth factor expression via proteinaseactivated receptor- 2 and mitogen-activated protein kinase pathways in bone marrow stromal cells in acute myeloid leukemia. Leuk Lymphoma 51: 1550-1558, 2010.

37. DeFea KA, Zalevsky J, Thoma MS, Dery O, Mullins RD and Bunnett NW: Beta-arrestin-dependent endocytosis of proteinaseactivated receptor 2 is required for intracellular targeting of activated ERK1/2. J Cell Biol 148: 1267-1281, 2000.

38. Stalheim L, Ding Y, Gullapalli A, et al: Multiple independent functions of arrestins in the regulation of protease-activated receptor-2 signaling and trafficking. Mol Pharmacol 67: 78-87, 2005.

39. Kanke T, Macfarlane SR, Seatter MJ, et al: Proteinase-activated receptor-2-mediated activation of stress-activated protein kinases and inhibitory kappa B kinases in NCTC 2544 keratinocytes. J Biol Chem 276: 31657-31666, 2001.

40. Lidington EA, Steinberg R, Kinderlerer AR, et al: A role for proteinase-activated receptor 2 and PKC-epsilon in thrombinmediated induction of decay-accelerating factor on human endothelial cells. Am J Physiol Cell Physiol 289: C1437-C1447, 2005.

41. Xiao YQ, Malcolm K, Worthen GS, et al: Cross-talk between ERK and p38 MAPK mediates selective suppression of proinflammatory cytokines by transforming growth factor-beta. J Biol Chem 277: 14884-14893, 2002

42. Tancharoen S, Sarker KP, Imamura T, et al: Neuropeptide release from dental pulp cells by RgpB via proteinase-activated receptor-2 signaling. J Immunol 174: 5796-5804, 2005.

43. Fyfe M, Bergstrom M, Aspengren S and Peterson A: PAR-2 activation in intestinal epithelial cells potentiates interleukin-1betainduced chemokine secretion via MAP kinase signaling pathways. Cytokine 31: 358-367, 2005.

44. Weis SM and Cheresh DA: Tumor angiogenesis: molecular pathways and therapeutic targets. Nat Med 17: 1359-1370, 2011.

45. Barry GD, Suen JY, Le GT, Cotterell A, Reid RC and Fairlie DP Novel agonists and antagonists for human protease activated receptor 2. J Med Chem 53: 7428-7440, 2010. 